\title{
Enhanced Endogenous Amino Acids and Energy Metabolism Level for cAMP Biosynthesis by Arthrobacter sp. CCTCC 2013431 with Citrate as Cosubstrate
}

\author{
Zhigang Li \\ Henan Institute of Science and Technology \\ Baofeng Chen \\ Henan Institute of Technology \\ Yang Gu \\ Henan Institute of Science and Technology \\ Hai Tan \\ Henan Institute of Science and Technology \\ Zhonghua Zhang \\ Henan Institute of Science and Technology \\ Jingling Chang ( $\square$ changjl001@126.com ) \\ Henan Institute of Science and Technology https://orcid.org/0000-0001-8063-3147
}

\section{Research Article}

Keywords: cAMP, citrate, amino asids, energy metabolism, oxidative stress

Posted Date: May 21st, 2021

DOl: https://doi.org/10.21203/rs.3.rs-498212/v1

License: (c) (i) This work is licensed under a Creative Commons Attribution 4.0 International License. Read Full License

Version of Record: A version of this preprint was published at Biotechnology Letters on August 14th, 2021. See the published version at https://doi.org/10.1007/s10529-021-03170-6. 


\section{Abstract}

Objectives In our previous study, citrate was used as auxiliary energy substance for improving cAMP fermentation performance, however, the regulation mechanism of citrate on improved cAMP contents was not clear. To elucidate the regulation mechanism, cAMP fermentations with/without citrate addition were conducted in a $7 \mathrm{~L}$ fermentor using Arthrobactersp. CCTCC 2013431 and assays on key enzymes activities, energy metabolism level, amino acids contents and peroxidation level were performed.

Results With $3 \mathrm{~g} / \mathrm{L}$-broth sodium citrate added, cAMP concentration and conversion yield from glucose reached $4.34 \mathrm{~g} / \mathrm{L}$ and $0.076 \mathrm{~g} / \mathrm{g}$ which were improved by $30.7 \%$ and $29.8 \%$, respectively, when compared with those of control. Citrate changed carbon flux distribution among different routes and more carbon flux was directed into pentose phosphate pathway beneficial to cAMP synthesis. Meanwhile, energy metabolism together with precursor amino acids levels were improved significantly owing to strengthened metabolic intensity of tricarboxylate cycle by exogenous citrate utilization which provided energy and substance basis for cAMP production. Moreover, higher glutamate synthesis and oxidative stress caused by citrate addition consumed excessive NADPH derived from pentose phosphate pathway by which feedback suppression for pentose phosphate pathway was relieved efficiently.

Conclusion Citrate promoted cAMP fermentation production by Arthrobactersp. CCTCC2013431 due to enhanced precursor amino acids, energy metabolism level and relieved feedback suppression for pentose phosphate pathway.

\section{Introduction}

Cyclic adenosine monophosphate (cAMP) is an important physiological active substance broadly existed in living cells. As a second messenger, cAMP has numerous regulation functions, for instance expanding blood vessels, relaxing smooth muscle, stimulating adrenaline secretion and promoting nerve regeneration (Mcphee et al. 2005; Sholokh and Klussmann 2021). Owing to its significant functions, CAMP was extensively applied in treatment of cardio-cerebrovascular diseases and area of animal feed additive attracting extensively attentions (Liu et al. 2018). cAMP can be produced via three different processes: chemical synthesis (Lelle et al. 2019), enzymatic (Sun et al. 2021), and fermentation processes (Niu et al. 2018). Among these approaches, fermentation production by microorganism has attracted increasing attention, because the process is economical, sustainable and environmental-friendly as compared with complicated chemical synthesis. As far, studies concerning cAMP fermentation mainly focus on strain screening (Song et al. 2010), genetic modification (Niu et al. 2020) and metabolic regulation on the fermentation process (Niu et al. 2013, 2018).

CAMP is synthesized from ATP directly catalyzed by adenylate cyclase in living cells and abundant ATP supply is beneficial for cAMP production (Li et al. 2018). In aerobic fermentation, energy for ATP formation is mainly from NADH oxidation reaction coupled with electron transport chain, whereas tricarboxylate cycle is the major route providing hydride for $N A D^{+}$ reduction to NADH ( $\mathrm{Li}$ et al. 2020). Moreover, the carbon skeleton of ATP are provided by pentose phosphate pathway and precursor amino acids are necessary for ATP via de novo synthesis pathway. However, it was discovered that carbon flux between glycolytic pathway and tricarboxylate cycle was mismatched and excess carbon flux was distributed for coproducts accumulation, meanwhile, plenty of NADH was also consumed as cofactor for coproducts synthesis which influenced cAMP production due to wastage of carbon and lower ATP generation (Chen et al. 2010a). Therefore, abundant energy supply and appropriate carbon flux distribution among different pathways are favourable for cAMP high-level synthesis.

Sodium citrate, a commonly used chemical reagent, plays an important function in metabolic regulation of microorganisms (Chen et al. 2010b). It could redistribute the carbon flux between pentose phosphate pathway and glycolytic pathways and direct more flux into pentose phosphate pathway resulting in less organic acid synthesis and NADH consumption (Chen et al. 2005; Wang et al. 2020). The utilization of citrate coupling with glucose could drastically decrease carbon flux in glycolytic pathway, and there was almost no acid production with B. subtilis as the production strain (Chen et al. 2020). 
Moreover, citrate can also be utilized as auxiliary energy substrate to improve intracellular ATP and ATP/ADP levels for Sadenosylmethionine and glutathione coproduction (Wang et al. 2013). In our previous study, $3 \mathrm{~g} / \mathrm{L}$-broth sodium citrate added at $24 \mathrm{~h}$ increased cAMP production greatly in shake flasks and the manipulating condition was determined as optimal for CAMP production (Li et al. 2018). However, the regulation mechanism of citrate on improved cAMP contents was not clear.

In this study, $3 \mathrm{~g} / \mathrm{L}$-broth sodium citrate was added into a $7 \mathrm{~L}$ bioreactor at $24 \mathrm{~h}$ to enhance cAMP fermentation production by Arthrobactersp. CCTCC 2013431 and assays on key enzymes activities, energy metabolism level, amino acids contents and peroxidation level were performed to elucidate the regulation mechanism of citrate on cAMP biosynthesis.

\section{Materials And Methods}

\section{Microorganism and culture condition}

Arthrobacter sp. CCTCC 2013431 (azoguanine resistance) stored in our laboratory was used as production strain in this study. The strain was maintained on slant medium containing potato extract ( $200 \mathrm{~g}$ potato in $1 \mathrm{~L}$ water), guanine $0.05 \mathrm{~g} / \mathrm{L}$, peptone $10 \mathrm{~g} / \mathrm{L}, \mathrm{MgSO}_{4} 0.01 \mathrm{~g} / \mathrm{L}$ and agar $20 \mathrm{~g} / \mathrm{L}$, under the condition of $4^{\circ} \mathrm{C}$. For inoculum preparation, the microorganism stored in slant medium was transferred into shake flasks $(250 \mathrm{~mL})$ containing $25 \mathrm{~mL}$ seed medium containing: yeast extract $10 \mathrm{~g} / \mathrm{L}$, peptone $12 \mathrm{~g} / \mathrm{L}$, glucose $10 \mathrm{~g} / \mathrm{L}$, beef extract $10 \mathrm{~g} / \mathrm{L}, \mathrm{NaCl} 4 \mathrm{~g} / \mathrm{L}$ and urea $5 \mathrm{~g} / \mathrm{L}$. The $\mathrm{pH}$ of the medium was adjusted to 7.4 before autoclaving. The inoculum would be transferred into fermentation reactors or shake flasks with a volume ratio of $10 \%$ for fermentation culture, after previous culture at $30^{\circ} \mathrm{C}$ on a rotary shaker incubator at $220 \mathrm{r} / \mathrm{min}$ for $24 \mathrm{~h}$. Fermentation batches were conducted in a $7 \mathrm{~L}$ stirred tank bioreactor (Baoxing Bioengineering Co., China) containing $5 \mathrm{~L}$ fermentation medium contained: $\mathrm{K}_{2} \mathrm{HPO}_{4} 10 \mathrm{~g} / \mathrm{L}$, glucose $80 \mathrm{~g} / \mathrm{L}, \mathrm{KH}_{2} \mathrm{PO}_{4} 12 \mathrm{~g} / \mathrm{L}$, peptone $5 \mathrm{~g} / \mathrm{L}$, urea $10 \mathrm{~g} / \mathrm{L}, \mathrm{MgSO}_{4} \cdot 7 \mathrm{H}_{2} \mathrm{O}$ $3 \mathrm{~g} / \mathrm{L}$, biotin $0.005 \mathrm{~g} / \mathrm{L}$, hypoxanthine $2 \mathrm{~g} / \mathrm{L}, \mathrm{CoCl}_{2} 0.01 \mathrm{~g} / \mathrm{L}$. The bioreactor was equipped with $\mathrm{pH}$ and $\mathrm{DO}$ electrodes and the fermentation parameters were measured and regulated by a digital control system. The fermentation conditions were controlled as follows: temperature $30^{\circ} \mathrm{C}$, aeration rate $0.16-0.3 \mathrm{vvm}$, agitation rate $350-450 \mathrm{r} / \mathrm{min}$. The pH was controlled above 6.9 automatically by feeding $4 \mathrm{~mol} / \mathrm{L} \mathrm{NaOH}$ solution. Soybean oil was utilized as the antifoam. For feeding batches, 3 $\mathrm{g} / \mathrm{L}$-broth sodium citrate was transferred into the fermentation broth at $24 \mathrm{~h}$ for one time.

\section{Analytical Methods}

The glucose concentration was determined by DNS method. The microorganism concentrations were determined by measuring the optical density at $600 \mathrm{~nm}\left(\mathrm{OD}_{600}\right)$ and converted to the dry cell weight (DCW) by an appropriate calibration curve $\left(\mathrm{DCW}(\mathrm{g} / \mathrm{L})=0.36 \times \mathrm{OD}_{600}\right)$. cAMP and hypoxanthine concentrations were measured by HPLC (Agilent 1206) with a Diamonsil-C18 column $(250 \mathrm{~mm} \times 4.6 \mathrm{~mm} \times 5 \mu \mathrm{m})$ under the conditions described in previous publication (Niu et al. 2018).

For the assay of intracellular ATP, AMP, NADH and NAD ${ }^{+}$contents, the samples were measured by HPLC (Agilent 1206) described in previous research (Du et al. 2006; Wang et al. 2013) using a ZORBAX SB-Aq column $(250 \mathrm{~mm} \times 4.6 \mathrm{~mm})$ at $30^{\circ} \mathrm{C}$ and a spectrophotometer at $254 \mathrm{~nm} .50 \mathrm{~mL}$ culture broth gained at different fermentation phases were treated by liquid nitrogen to quench the cellular metabolism, then the cells were harvested by centrifugation under the condition of 10,000 $\mathrm{r} / \mathrm{min}$ for $10 \mathrm{~min}$ at $4^{\circ} \mathrm{C}$. The cells were washed twice by $0.3 \mathrm{~mol} / \mathrm{L}$ PBS solution $(\mathrm{pH} 7.4)$ and the cells suspension was lysed by ultrasonication for $15 \mathrm{~min}$ under the condition of ice bath, then supernatant obtained via centrifuged (10000 r/min for 10 min at $4^{\circ} \mathrm{C}$ ) was utilized for determination. $\mathrm{NADP}^{+}$and NADPH concentrations were determined according to Zhang (2000).

Intracellular amino acids concentrations were determined according to AccQ-Tag method developed by Waters corporation and samples were treated with the method described in previous publication (Wang et al. 2020). $50 \mathrm{~mL}$ cell culture grown under different conditions were harvested at $26,36,50$ and $60 \mathrm{~h}$ by centrifugation $(10,000 \mathrm{r} / \mathrm{min}, 10 \mathrm{~min})$. The cells were washed twice with ultrapure water and re-suspended in $1 \mathrm{~mL}$ trichloroacetic acid solution (10\%) under the condition of $37^{\circ} \mathrm{C}$ 
for $10 \mathrm{~min}$. Then the mixtures were boiled for $15 \mathrm{~min}$. Cell debris was discarded by centrifugation (10,000 r/min, $10 \mathrm{~min}$, $4^{\circ} \mathrm{C}$ ), and the supernatants were analyzed with HPLC according to the AccQ-Tag method developed by Waters corporation.

5-cyano-2, 3-ditolyl tetrazoliumchloride (CTC) was widely used as a cellular redox indicator of respiratory activity. Cell viability (respiration activity) was analyzed by CTC Rapid Staining Kit (Dojindo Laboratories, Japan) as defined in the specification with little modification (Zeng et al. 2015) and the fluorescence signal was detected by a fluorescence spectrophotometer with excitation wavelength at $488 \mathrm{~nm}$ and emission at $620 \mathrm{~nm}$. The cell viability was represented by the obtained fluorescence intensity.

Enzyme assays were performed spectrophotometrically for pyruvate kinase (PK, EC 2.7.1.40), phosphoenolpyruvate carboxylase (PEPC, EC 4.1.1.31), 6-phosphoglucose dehydrogenase (G6PDH, EC 1.1.1.49) (Cao et al.2013), citrate synthases (CS, EC 2.3.3.1), aspartate aminotransferase (AAT, EC 2.6.1.1) (Xia et al. 2014), and glutamate dehydrogenase (GDH, EC 1.4.1.2) (Chen et al. 2015). The assay methods for above enzymes were based on corresponding literatures with some modifications. The activities of above enzymes were monitored at $340 \mathrm{~nm}$ unless otherwise stated. One unit of enzyme activity was defined as the amount of enzyme needed to oxidise $1 \mu \mathrm{mol}$ of $\mathrm{NAD}(\mathrm{P}) \mathrm{H}$ or to reduce $1 \mu \mathrm{mol}$ of $\mathrm{NAD}(\mathrm{P})^{+}$per minute. Coomassie Brilliant Blue method was utilized for protein determination.

Intracellular ROS contents were measured utilizing dihydroethidium (DHE) in accordance to the protocol for the DHE-ROS assay kit (Shanghai BestBio SCIDTECH CO. LTD, China). DHE was oxidized to fluorescent substance by the ROS. The fluorescent signal was observed (excitation at $535 \mathrm{~nm}$ and emission at $610 \mathrm{~nm}$ ) by a fluorescence spectrophotometer (Tianjin Gangdong SCIITECH CO. LTD, China). The intracellular MDA content was an indicator of oxidative damage level. It was assayed by a colorimetric reaction of MDA with thiobarbituric acid as described by Zeng (2016).

\section{Statistical analysis}

For determination of each parameters mentioned above, triplicate experiments were carried out and the mean values were calculated. Student's t test was employed to investigate statistical differences. Samples with $P$ values of $<0.05$ were considered statistically different.

\section{Results And Discussion}

\section{Citrate enhanced cAMP fermentation performance in Arthrobacter sp. CCTCC 2013431}

Citrate can be utilized as auxiliary energy substrate to improve intracellular ATP level and direct more carbon flux into pentose phosphate pathway leading to the increase of nucleotides production (Chen et al. 2010a; ). In our previous study, 3 $\mathrm{g} / \mathrm{L}$-broth sodium citrate added at $24 \mathrm{~h}$ was determined as optimal manipulating condition for cAMP fermentatiom conducted in shake flasks ( $\mathrm{Li}$ et al. 2018). To investigate the metabolic mechanism, batch fermentations with the optimal condition were conducted in a $7 \mathrm{~L}$ stirred tank bioreactor. As presented in Fig. 1, due to the addition of citrate, final cAMP concentration and conversion yield from glucose reached $4.34 \mathrm{~g} / \mathrm{L}$ and $0.076 \mathrm{~g} / \mathrm{g}$ which were improved by $30.7 \%$ and $29.8 \%$, respectively, when compared with those of control (without citrate addition). It was $24 \mathrm{~h}$ after which cAMP contents as well as synthesis rates were enhanced obviously and maintained at higher levels than those of control suggesting that citrate addition did accelerate cAMP production. The final $\mathrm{OD}_{600}$ and glucose consumption amounts in fermentation with citrate added were almost equal to those of control, however, $\mathrm{OD}_{600}$ in control fermentation achieved its peak value at $43 \mathrm{~h}$ and then decreased gradually suggesting that cell viability and metabolic intensity had started to decline during the later period, while in citrate added fermentation, cell concentrations kept increasing during the whole period (Fig. 1a). The data of cell viability and $\mathrm{CO}_{2}$ assay were in support of this deduction directly. The fluorescence intensity of cell suspension after suitable dilution and CTC treatment was detected as an indicator of cell viability (respiration activity), and $\mathrm{CO}_{2}$ content in discharge gas could represent cell aerobic respiration level. As shown in Fig. $1 \mathrm{~cd}$, after $24 \mathrm{~h}$, cell viability and $\mathrm{CO}_{2}$ contents were improved significantly by citrate and maintained at higher levels than those of control, however, cell viability and $\mathrm{CO}_{2}$ 
contents were almost equal under the two conditions during $0-24 \mathrm{~h}$, suggesting that aerobic respiration and energy metabolism level was enhanced obviously after $24 \mathrm{~h}$ in citrate added fermentation.

In addition, after $24 \mathrm{~h}$, hypoxanthine concentrations were maintained at lower levels about $0.2 \mathrm{~g} / \mathrm{L}$ in both fermentations suggesting that CAMP was not synthesized by salvage pathway but via purine nucleotide de novo pathway. In this case, sufficient supplies of phosphoribosyl pyrophosphate (PRPP) and precursor amino acids were required for high-level cAMP biosynthesis. PRPP formation related to carbon flux distribution between glycolysis and pentose phosphate pathway whereas precursor amino acids mainly included aspartate as well as glutamate whose carbon skeletons derived from tricarboxylate cycle. Moreover, cAMP is synthesized from ATP directly catalyzed by adenylate cyclase and abundant ATP supply is beneficial for cATP synthesis. Hence we attempt to reveal the regulation mechanism of citrate on cAMP biosynthesis via investigating the change of key enzymes activities, energy metabolism levels and amino acids synthesis.

\section{Citrate enhanced intracellular NADH and ATP level during fermentation using Arthrobacter sp. CCTCC 2013431}

In living cell, cAMP is synthesized from ATP directly catalyzed by adenylate cyclase and abundant ATP supply is beneficial for cAMP synthesis. In aerobic fermentation process, ATP is mainly formed via NADH oxidation reaction coupled with electron transport chain, namely oxidative phosphorylation reaction. As an auxiliary energy substance, citrate could strengthen energy metabolism and enhance ATP regeneration for lactic acid (Kang et al. 2016; Comasio et al. 2019), pyruvate (Zhou et al.2010) and nucleotide production (Chen et al.2010a) efficiently. Therefore, we hypothesized that citrate might increase intracellular ATP level, further promoting cAMP synthesis. To confirm the assumption, NADH and ATP levels in fermentations with/without citrate addition were determined and the results were shown in Fig. 2.

As shown in Fig. 2a, owing to citrate added, intracellular $\mathrm{NADH} / \mathrm{NAD}^{+}$ratios were improved obviously and maintained at higher levels when compared with those of control. The production of cAMP by Arthrobactersp. CCTCC 2013431 was an aerobic fermentation process and NADH regeneration was mainly achieved by strengthened NAD ${ }^{+}$-linked dehydrogenase reactions presence in tricarboxylate cycle. In the case, citrate enhanced tricarboxylate cycle metabolic intensity and NADH regeneration, further improved $\mathrm{NADH} / \mathrm{NAD}^{+}$ratios. Moreover, $\mathrm{NADH}$ can be reoxidized to $\mathrm{NAD}^{+}$by electron transport chain which accompanied by plenty of ATP synthesis. High NADH/NAD ${ }^{+}$ratios suggested that energy metabolism was strengthened by citrate and ATP might be generated more efficiently.

ATP assay results also verified our deduction. Intracellular ATP/AMP ratios were enhanced obviously as result of the addition of citrate when compared with those of control (Fig. 2b), which in agreement with NADH/NAD ratios assay results. What deserve to be mentioned is that ATP and AMP contents in citrate added fermentation were both higher than those of control indicating that citrate was not only strengthened the phosphorylation reactions rendering energy for ATP formation but also enhanced purine nucleotide (AMP) synthesis. Continuous supplement of AMP and energy for ATP phosphorylation provided sufficient substance and energy for cAMP fermentation production.

\section{Citrate Improved Intracellular Amino Acids Levels For Camp Synthesis}

Precursor amino acids were necessary for cAMP synthesis via de novo pathway and the change of intracellular amino acids amounts could influence cell growth, physiological status and product synthesis. So intracellular amino acids contents were assayed to investigate the causes of higher CAMP formation capacity in citrate added fermentation. 18 kind of intracellular amino acids were detected by HPLC according to AccQ-Tag method and 6 of them were increased obviously in concentrations as result of citrate addition when compared with those of control, as displayed in Fig. 3. Due to citrate addition, intracellular lysine, aspartate, glutamate, glutamine, threonine and arginine contents were improved by $59.4 \%$, $167,7 \%, 96.9 \%, 673.9 \%, 365.2 \%$ and $76.7 \%$ (at $50 \mathrm{~h}$ ), respectively, which were beneficial for cell growth and cAMP production. Among the 6 kind of amino asids, aspartate and glutamine were necessary for cAMP synthesis via de novo pathway which were deemed as precursor amino acids. Moreover, lysine, aspartate and threonine were synthesized on basis of oxaloacetate 
as the carbon skeleton donator, and a-ketoglutarate was the carbon skeleton donator for glutamate, glutamine and arginine biosynthesis. Oxaloacetate and a-ketoglutarate were derived from tricarboxylate cycle. It can be deduced that exogenous citrate activated the metabolic intensity of tricarboxylate cycle, enhanced some metabolites levels (such as oxaloacetate and a-ketoglutarate) resulting in the significant improvement of precursor amino acids levels together with NADH/NAD ${ }^{+}$ ratios, which further accelerated cAMP production.

\section{The effects of citrate on activities of key enzymes in cAMP synthesis related metabolic pathway}

In certain metabolic pathway, the change of key enzymes activities reflected metabolic flux distribution state and the metabolic pathway for cAMP formation had been elucidated in previous study (Niu et al. 2013). To investigate the metabolic response of cAMP biosynthesis towards citrate, the activities of key enzymes in tricarboxylate cycle, glycolysis, pentose phosphate pathway and some amino acids synthesis pathway were assayed and the detected results were exhibited in Table 1 and Fig. 4.

Table 1

Comparison of key enzymes activities in cAMP fermentations with/without citrate addition.

\begin{tabular}{|c|c|c|c|c|c|c|c|c|c|c|c|c|c|c|}
\hline \multirow{2}{*}{$\begin{array}{l}\text { Time } \\
\text { (h) }\end{array}$} & \multicolumn{2}{|c|}{ G6PDH } & \multicolumn{2}{|l|}{ PK } & \multicolumn{2}{|c|}{ PEPC } & \multicolumn{2}{|l|}{ CS } & \multicolumn{2}{|l|}{$\mathrm{ICDH}$} & \multicolumn{2}{|l|}{ AAT } & \multicolumn{2}{|c|}{ NADPH-GDH } \\
\hline & A & B & A & B & A & B & A & B & A & B & A & B & A & B \\
\hline 26 & $\begin{array}{l}3.42 \\
\pm \\
0.12\end{array}$ & $\begin{array}{l}3.72 \\
\pm \\
0.14\end{array}$ & $\begin{array}{l}7.33 \\
\pm \\
0.13\end{array}$ & $\begin{array}{l}7.14 \\
\pm \\
0.12\end{array}$ & $\begin{array}{l}4.85 \\
\pm \\
0.13\end{array}$ & $\begin{array}{l}5.02 \\
\pm \\
0.16\end{array}$ & $\begin{array}{l}0.43 \\
\pm \\
0.05\end{array}$ & $\begin{array}{l}0.40 \\
\pm \\
0.02\end{array}$ & $\begin{array}{l}1.89 \\
\pm \\
0.15\end{array}$ & $\begin{array}{l}1.95 \\
\pm \\
0.12\end{array}$ & $\begin{array}{l}5.23 \\
\pm \\
0.11\end{array}$ & $\begin{array}{l}5.62 \\
\pm \\
0.13\end{array}$ & $\begin{array}{l}0.76 \\
\pm \\
0.02\end{array}$ & $\begin{array}{l}0.83 \\
\pm \\
0.03\end{array}$ \\
\hline 36 & $\begin{array}{l}3.33 \\
\pm \\
0.13\end{array}$ & $\begin{array}{l}4.02 \\
\pm \\
0.12\end{array}$ & $\begin{array}{l}9.46 \\
\pm \\
0.14\end{array}$ & $\begin{array}{l}6.86 \\
\pm \\
0.18\end{array}$ & $\begin{array}{l}4.68 \\
\pm \\
0.14\end{array}$ & $\begin{array}{l}5.16 \\
\pm \\
0.14\end{array}$ & $\begin{array}{l}0.45 \\
\pm \\
0.02\end{array}$ & $\begin{array}{l}0.32 \\
\pm \\
0.03\end{array}$ & $\begin{array}{l}1.78 \\
\pm \\
0.14\end{array}$ & $\begin{array}{l}2.03 \\
\pm \\
0.11\end{array}$ & $\begin{array}{l}5.45 \\
\pm \\
0.13\end{array}$ & $\begin{array}{l}7.43 \\
\pm \\
0.13\end{array}$ & $\begin{array}{l}0.64 \\
\pm \\
0.03\end{array}$ & $\begin{array}{l}0.86 \\
\pm \\
0.02\end{array}$ \\
\hline 50 & $\begin{array}{l}3.05 \\
\pm \\
0.10\end{array}$ & $\begin{array}{l}3.63 \\
\pm \\
0.14\end{array}$ & $\begin{array}{l}8.12 \\
\pm \\
0.12\end{array}$ & $\begin{array}{l}6.44 \\
\pm \\
0.14\end{array}$ & $\begin{array}{l}4.35 \\
\pm \\
0.10\end{array}$ & $\begin{array}{l}4.82 \\
\pm \\
0.13\end{array}$ & $\begin{array}{l}0.42 \\
\pm \\
0.03\end{array}$ & $\begin{array}{l}0.30 \\
\pm \\
0.02\end{array}$ & $\begin{array}{l}1.68 \\
\pm \\
0.12\end{array}$ & $\begin{array}{l}1.85 \\
\pm \\
0.13\end{array}$ & $\begin{array}{l}4.92 \\
\pm \\
0.12\end{array}$ & $\begin{array}{l}6.32 \\
\pm \\
0.13\end{array}$ & $\begin{array}{l}0.60 \\
\pm \\
0.02\end{array}$ & $\begin{array}{l}0.75 \\
\pm \\
0.02\end{array}$ \\
\hline 60 & $\begin{array}{l}2.54 \\
\pm \\
0.11\end{array}$ & $\begin{array}{l}3.15 \\
\pm \\
0.13\end{array}$ & $\begin{array}{l}5.45 \\
\pm \\
0.12\end{array}$ & $\begin{array}{l}4.75 \\
\pm \\
0.15\end{array}$ & $\begin{array}{l}3.81 \\
\pm \\
0.16\end{array}$ & $\begin{array}{l}4.14 \\
\pm \\
0.12\end{array}$ & $\begin{array}{l}0.27 \\
\pm \\
0.02\end{array}$ & $\begin{array}{l}0.20 \\
\pm \\
0.03\end{array}$ & $\begin{array}{l}1.72 \\
\pm \\
0.11\end{array}$ & $\begin{array}{l}1.82 \\
\pm \\
0.13\end{array}$ & $\begin{array}{l}4.25 \\
\pm \\
0.13\end{array}$ & $\begin{array}{l}5.46 \\
\pm \\
0.13\end{array}$ & $\begin{array}{l}0.43 \\
\pm \\
0.02\end{array}$ & $\begin{array}{l}0.58 \\
\pm \\
0.03\end{array}$ \\
\hline
\end{tabular}

Note: A: control, B: with $3 \mathrm{~g} / \mathrm{L}$-broth sodium citrate added at $24 \mathrm{~h}$, the unite of enzyme activities was $10^{-2} \mathrm{U} / \mathrm{mg}$-protein.

6-phosphoglucose dehydrogenase (G6PDH) was the key enzyme connecting glycolysis and pentose phosphate pathway, whose activity reflected the distribution of carbon flux between two routes. Pyruvate kinase (PK) was the rate-limiting enzyme whose activity related to the metabolic intensity of glycolysis pathway directly. As shown in Table 1, due to the addition of citrate, the activities of G6PDH were promoted obviously with a increment of $21.6 \%$ (at $36 \mathrm{~h}$ ), meanwhile, PK activities were decreased evidently with a reduction of $27.5 \%$ (at $36 \mathrm{~h}$ ), when compared with those of control. It indicated that more carbon flux was distributed to pentose phosphate pathway for cAMP synthesis and glycolysis pathway was weakened correspondingly.

The activities of phosphoenolpyruvate carboxylase (PEPC), citrate synthases (CS) and isocitrate dehydrogenase (ICDH) were also assayed to illustrate the influence of citrate on tricarboxylate cycle. As presented in Table 1, citrate inhibited the activities of CS evidently with a decrease of $28.9 \%$ (at $36 \mathrm{~h}$ ), while ICDH and PEPC were stimulated to some extent with increasments of $14.1 \%$ and $10.3 \%$ (at $36 \mathrm{~h}$ ), respectively, as compared to control. CS is the rate-limiting enzyme in tricarboxylate cycle which catalyzed the reaction of oxaloacetic acid and acetyl-coA for citric acid synthesis. Here, CS and PK were inhibited greatly by citrate simultaneously suggesting that less carbon flux was injected into tricarboxylate cycle via citric acid synthesis reaction. However, enhanced ICDH activities and $2 \mathrm{~g} / \mathrm{L}$ exogenous sodium citrate consumption (Fig. 1b) indicated that exogenous citrate was utilized and injected into tricarboxylate cycle as cosubstrate via the transformation reaction from citrate to isocitric acid catalyzed by ICDH. In addition, improved PEPC activities indicated that more 
phosphoenolpyruvate was transformed to oxaloacetate by which insufficient metabolites in tricarboxylate cycle would be replenished. Therefore, it suggested that the metabolic intensity of tricarboxylate cycle would be enhanced to some extent owing to exogenous citrate utilization and more oxaloacetate synthesis, which had been proved by improved NADH/NAD ratios. Furthermore, some derivatives such as amino acids derived from tricarboxylate cycle might be produced in excess and accumulated.

In order to find the cause for enhanced 6 amino acids mentioned above, the activities of aspartate aminotransferase (AAT) and NADPH-dependent glutamate dehydrogenase (NADPH-GDH) were detected. As shown in Table 1, AAT and NADPH-GDH activities were improved by citrate significantly with respective increments of $36.3 \%$ and $34.4 \%$ higher than those of control at $36 \mathrm{~h}$, which in favour of related amino acids synthesis. It was in good agreement with the amino acids assay result.

\section{The effects of citrate on intracellular redox state during cAMP fermentation period}

Intracellular NADPH/NADP ${ }^{+}$ratio was another important influence factor for cAMP synthesis, owing to the feedback inhibition of high ratios on G6PDH. As shown in Fig. 5a, NADPH/NADP ${ }^{+}$ratios were decreased obviously by citrate with $24.5 \%$ reduction than control at $36 \mathrm{~h}$. In general, citrate directed more carbon flux into pentose phosphate pathway supplying substrate basis for cAMP synthesis, meanwhile, more NADPH was produced and accumulated, furthermore, NADPH/NADP ${ }^{+}$ ratio would be improved to some extent, in turn, high NADPH/NADP ${ }^{+}$ratio would inhibit the activity of G6PDH and restrain carbon flux injection into pentose phosphate pathway for cAMP synthesis in high proportion. Here, NADPH/NADP ${ }^{+}$ratios were not improved with higher G6PDH activities correspondingly in citrate added fermentation, on the contrary, the ratios were decreased significantly suggesting that there was other NADPH consuming route existed.

As described in previous study, high level energy metabolism was accompanied by more serious electron leakage from electron transport chain resulting in excessive ROS synthesis and severe oxidative stress (Li et al. 2020). Then, cell components would suffer from serious damage from oxidative stress which could be reflected by MDA level. So, change of intracellular ROS and MDA contents were assayed which reflected the cell oxidative stress state and damage degree, respectivyly. As shown in Fig. 5bc, intracellular ROS contents in fermentation with citrate added were higher than those of control obviously with average $30.1 \%$ increments after $36 \mathrm{~h}$, meanwhile, MDA levels in fermentations with/without citrate addition were almost equal at different fermentation time and increased gradually over time during whole fermentation period. It indicated that excessive NADPH derived from pentose phosphate pathway was partly consumed for the reduction of ROS aroused by citrate addition for intracellular redox balance maintenance, avoiding more serious cell damage than control. In addition, excessive NADPH was also utilized for abundant glutamate synthesis in citrate added fermentation due to its higher NADPH-GDH activities. Consequently, excessive NADPH was consumed by above two routes efficiently resulting in lower $\mathrm{NADPH} / \mathrm{NADP}^{+}$ratios and higher glutamate contents in citrate added fermentation, by which feedback suppression for pentose phosphate pathway was relieved efficiently. Finally, enhanced carbon flux, amino acids and energy metabolism levels promoted cAMP production synergistically.

\section{Conclusion}

Due to the addition of citrate, cAMP concentration and conversion yield from glucose were improved by $30.7 \%$ and $29.8 \%$, respectively, as compared with those of control conducted in a $7 \mathrm{~L}$ fermentor. To investigate the regulation mechanism of citrate on cAMP biosynthesis, activities of key enzymes, energy metabolism, amino acids contents and peroxidation level were assayed. The results demonstated that citrate changed carbon flux distribution among different routes and more carbon flux was directed into pentose phosphate pathway beneficial to cAMP synthesis. Meanwhile, energy metabolism together with precursor amino acids levels were improved significantly owing to improved metabolic intensity of tricarboxylate cycle by exogenous citrate utilization which provided energy and substance basis for cAMP production. Moreover, higher glutamate synthesis and oxidative stress caused by citrate addition consumed excessive NADPH derived from pentose phosphate pathway by which feedback suppression for pentose phosphate pathway was relieved efficiently.

Page 7/13 


\section{Declarations}

Funding This work was financially supported by the Science and Technology Breakthrough Plan of Henan Province 192102210193) and the Doctoral Scientific Research Foundation of Henan institute of science and technology (2015006).

Conflict of interest The authors declare that they have no conflict of interest.

Ethical approval This article does not contain any studies with human participants or animals performed by any of the authors.

\section{References}

CaoY, Mpofu E, Shi ZP (2013) A novel metabolic model incorporating directed signal flow diagram with enzymatic activities data for evaluating glutamate yield in glutamate fermentation. Biochem Eng J 77: 136-146.

Chen H, Cao X, Zhu NQ et al (2020) A stepwise control strategy for glutathione synthesis in Saccharomyces cerevisiae based on oxidative stress and energy metabolism. World J Microb Biot 36(8): 177-182.

Chen S, Chu J, Zhuang Y et al (2005) Enhancement of inosine production by Bacillus subtilis through suppression of carbon overflow by sodium citrate. Biotechnol Lett 27: 689-692.

Chen XC, Song H, Fang T et al (2010a) Enhanced cyclic adenosine monophosphate production by Arthrobacter A302 through rational redistribution of metabolic flux. Bioresource Techn 101: 3159-3163.

Chen Y, Li SY, Xiong J et al (2010b) The mechanisms of citrate on regulating the distribution of carbon flux in the biosynthesis of uridine 5'-monophosphate by Saccharomyces cerevisiae. Appl Microbiol Biotechnol 86: 75-81.

Chen Y, Liu Q, Chen XC et al (2015) Redirecting metabolic flux in Saccharomyces cerevisiae through regulation of cofactors in UMP production. J Ind Microbiol Biotechnol 42: 577-583.

Comasio A, Harth H, Weckx S et al (2019) The addition of citrate stimulates the production of acetoin and diacetyl by a citrate-positive Lactobacillus crustorum strain during wheat sourdough fermentation. Int J Food Microbiol 289: 88-105.

Du CY, Yan H, Zhang YP et al (2006) Use oxidoreduction potential as an indicator to regulate 1, 3-propanediol fermentation by Klebsiella pneumoniae. Appl Microbiol Biotechnol 69: 554-563.

Kang TS, Korber DR, Tanaka T (2013) Contributions of citrate in redox potential maintenance and ATP production: metabolic pathways and their regulation in Lactobacillus panis PM1. Appl Microbiol Biotechnol 97: 8693-8703.

Lelle M, Otte Maik, Thon S et al (2019) Chemical synthesis and biological activity of novel brominated 7-deazaadenosine-3', 5'-cyclic monophosphate derivatives. Bioorgan Med Chem 27(8):1704-1713.

Li S, Ji J, Hu S et al (2020) Enhancement of $\varepsilon$-poly-L-lysine production in Streptomyces griseofuscus by addition of exogenous astaxanthin. Bioproc Biosyst Eng 43(10): 1813-1821.

Li ZG, Chen BF, Fang ZB et al (2018) A novel fermentation process for cyclic adenosine monophosphate production based on citrate coupling hypoxanthine addition in pulses. Food and Fermentation Industries 44(11): 154-158.

Liu Q, Wu C, Huang S et al (2018) Decreased hyperpolarization-activated cyclic nucleotide-gated channels are involved in bladder dysfunction associated with spinal cord injury. Int J Mol Med 41(5): 2609-2618. 
Mcphee I, Gibson LC, Kewney J et al (2005) Cyclic nucleotide signalling: a molecular approach to drug discovery for Alzheimer's disease. Biochem Soc T 33: 1330-1332.

Niu HQ, Chen Y, Yao SW et al (2013) Metabolic flux analysis of Arthrobactersp. CGMCC 3584 for cAMP production based on

${ }^{13} \mathrm{C}$ tracer experiments and gas chromatography-mass spectrometry. J Biotechnol 168: 355-361.

Niu HQ, Wang JZ, Zhuang W et al (2018) Comparative transcriptomic and proteomic analysis of Arthrobacter sp CGMCC 3584 responding to dissolved oxygen for cAMP production. Sci Rep. https://doi.org/10.1038/ s41598-017-18889-4

Niu HQ, Sun XZ, Song J et al (2020) Knockout of pde gene in Arthrobacter sp. CGMCC 3584 and transcriptomic analysis of its effects on cAMP production. Bioproc Biosyst Eng 43(5): 839-850.

Sholokh A, Klussmann E. (2021) Local cyclic adenosine monophosphate signalling cascades-roles and targets in chronic kidney disease. Acta Physiol. https://doi.org/10.1111/apha.13641

Song H, Chen XC, Cao JM et al (2010) Directed breeding of an Arthrobacter mutant for high-yield production of cyclic adenosine monophosphate by $\mathrm{N}^{+}$ion implantation. Radiat Phys Chem 79: 826-830.

Sun Q C, Lv Y, Zhang C H et al (2021) Efficient preparation of c-di-AMP at gram-scale using an immobilized Vibrio cholerae dinucleotide cyclase DncV. Enzyme Microb Technol. https://doi.org/10.1016/j.enzmictec.2020.109700

Wang A, Tian W, ChengL et al (2020) Enhanced epsilon-Poly-L-Lysine production by the synergistic effect of epsilon-Poly-LLysine synthetase overexpression and citrate in Streptomyces albulus. Front Bioeng Biotech.

https://doi.org/10.3389/fbioe.2020.00288

Wang CY, Ren X, Yu C et al (2020) Physiological and transcriptional responses of Streptomyces albulus to acid stress in the biosynthesis of $\varepsilon$-Poly-L-lysine: mechanism and application. Front Microbiol. https://doi.org/10.3389/fmicb.2020.01379

Wang YL, Wang DH, Wei GY et al (2013) Improved co-production of S-adenosylmethionine and glutathione using citrate as an auxiliary energy substrate. Bioresource Techn 131: 28-32.

Xia J, Xu Z X, Xu H et al (2014) The regulatory effect of citric acid on the co-production of poly ( $\varepsilon$-lysine) and poly (Ldiaminopropionic acid) in Streptomyces albulus PD-1. Bioprocess Biosyst Eng 37: 2095-2103.

Zeng X, Chen X S, Gao Y, et al (2015) Continuously high reactive oxygen species generation decreased the specific $\varepsilon$-poly-Llysine formation rate in fed-batch fermentation using glucose and glycerol as a mixed carbon source. Process Biochem 50(12): 1993-2003.

Zeng X, Chen X S, Ren X D, et al (2016) Improved $\varepsilon$-poly-L-lysine productivity partly resulting from rapid cell growth in cultures using a glucose-glycerol mixed carbon source. Eng Life Sci 16(5): 1-10.

Zhou J, Liu L, Chen J (2010) Improved ATP supply enhances acid tolerance of Candida glabrata during pyruvic acid production. J Appl Microbiol 110: 44-53.

\section{Figures}



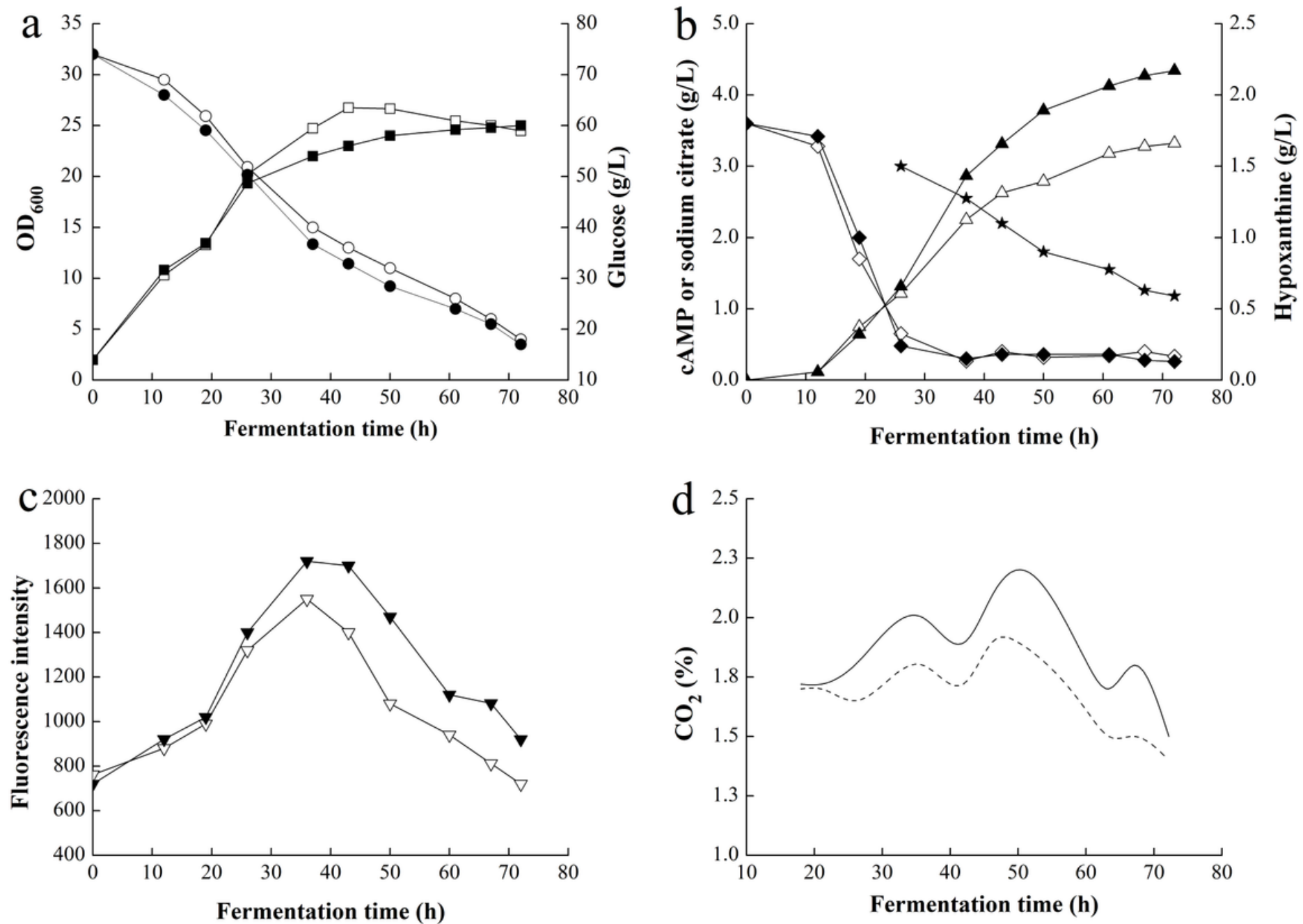

\section{Figure 1}

The effects of citrate addition on cAMP fermentation performance in a $7 \mathrm{~L}$ fermenter a, b, c: $\square / \square$ OD600, $\mathbf{Q} / \mathbf{g l u c o s e , ~} \mathbf{\Delta} /$

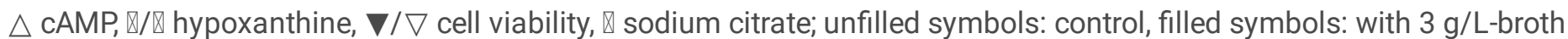
sodium citrate added at $24 \mathrm{~h}$; d: -- control, - with $3 \mathrm{~g} / \mathrm{L}$-broth sodium citrate added at $24 \mathrm{~h}$ 

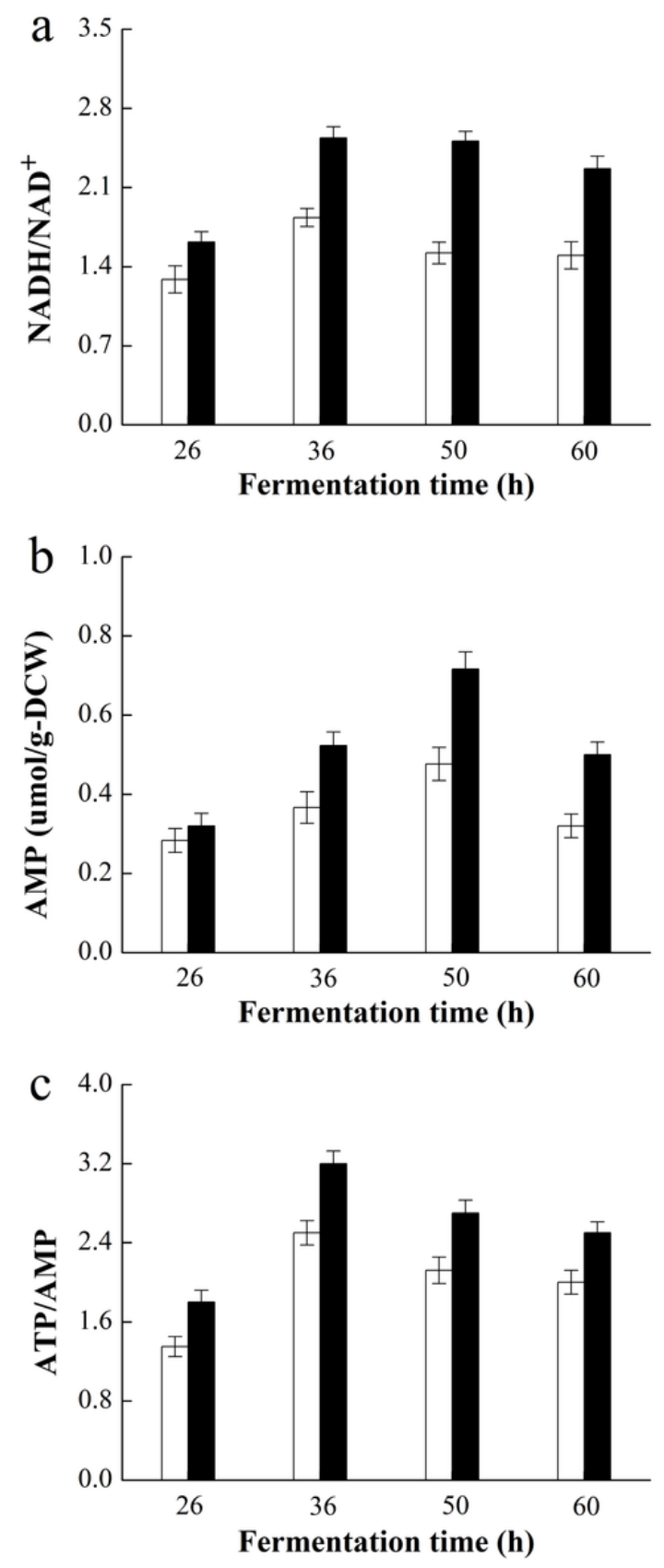

Figure 2

Comparison of intracellular ATP/AMP and NADH/NAD+ in fermentations with/without citrate addition White bar: control; black bar: with $3 \mathrm{~g} / \mathrm{L}$-broth sodium citrate added at $24 \mathrm{~h}$ 

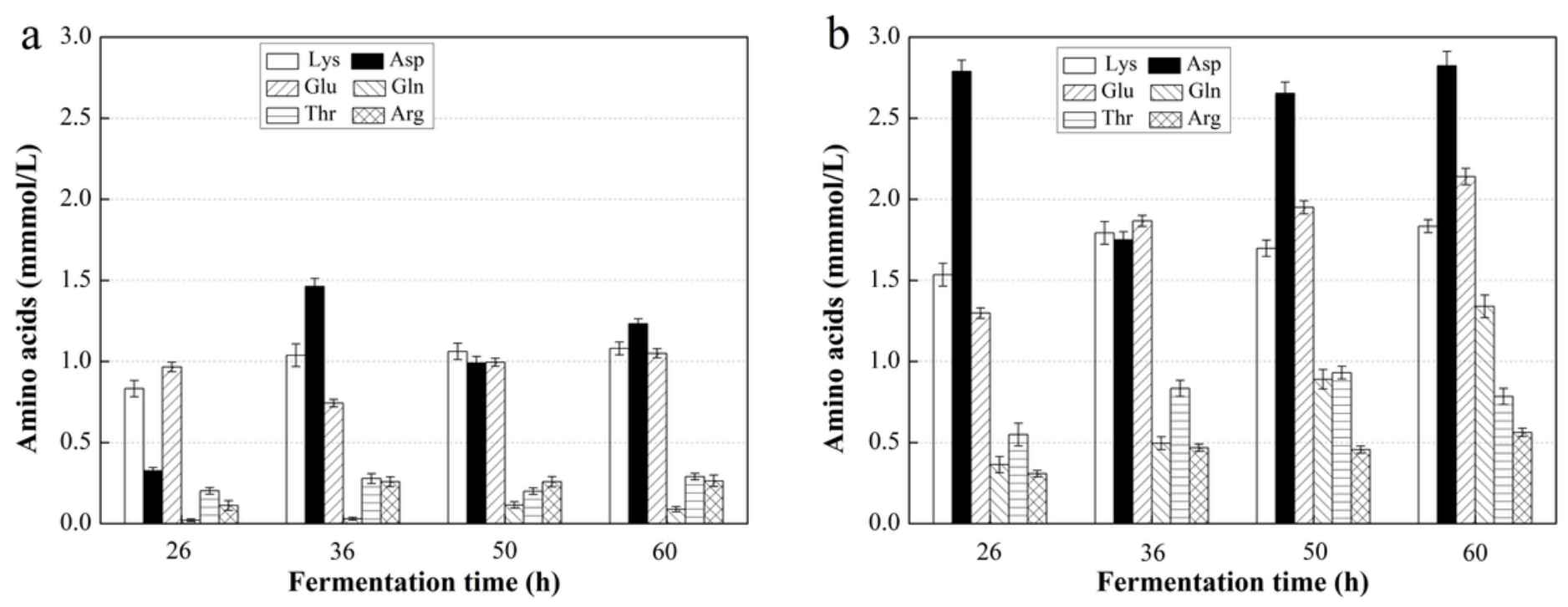

Figure 3

Comparison of intracellular amino acids amounts in cAMP fermentations with/without citrate addition a: control; b: with 3 $\mathrm{g} / \mathrm{L}$-broth sodium citrate added at $24 \mathrm{~h}$

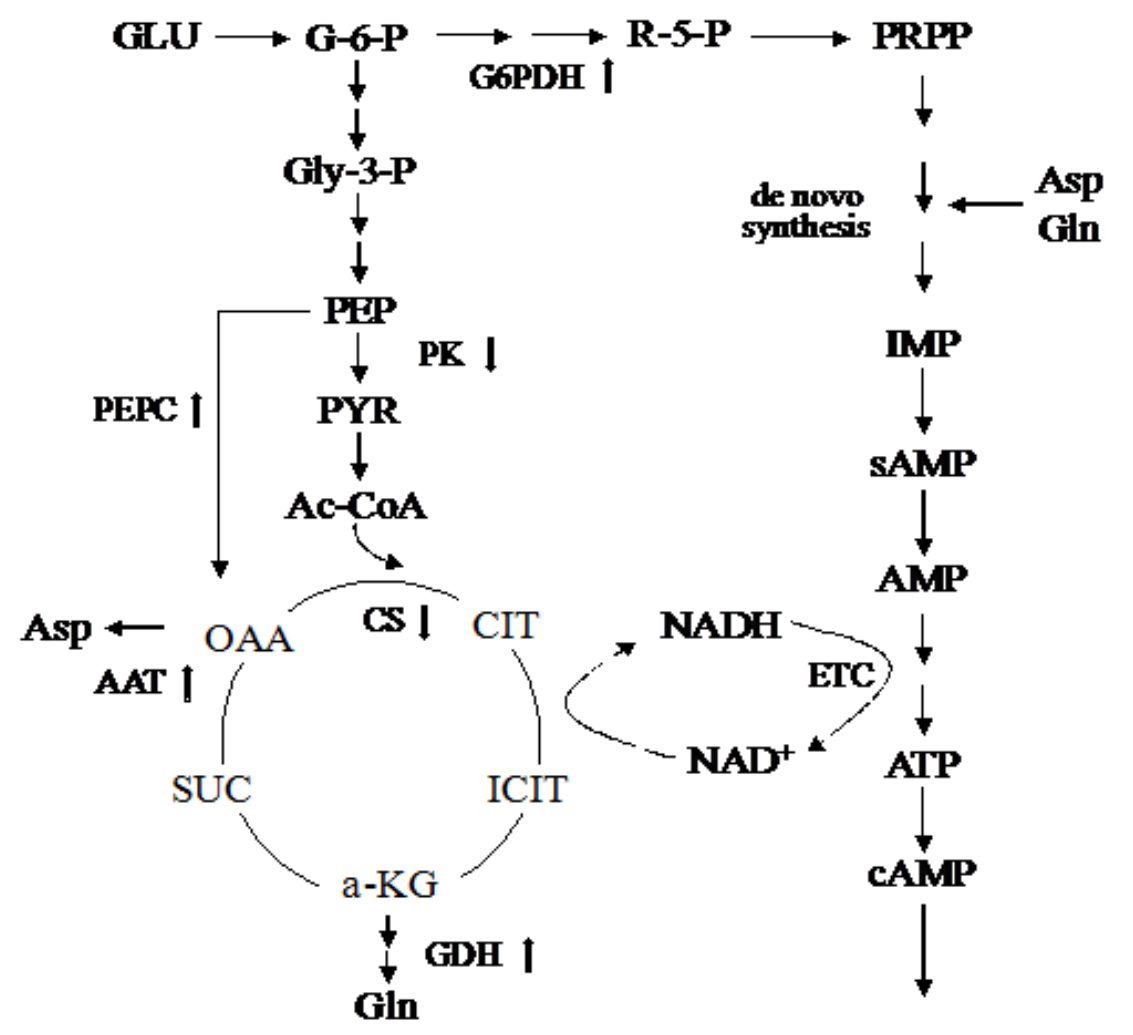

Figure 4

The schematic diagram for cAMP biosynthesis with citrate addition PRPP: phosphoribosyl pyrophosphate, IMP: inosine monophosphate, sAMP: adenylosuccinate, GLU: glucose, G-6-P: glucose-6-phosphate, Gly-3-P: 3-phosphoglycerate, PYR: pyruvate, PEP: phosphoenolpyruvate, CIT: citrate acid, ICIT: isocitrate, SUC: succinate, a-KG: a-ketoglutarate, OOA: oxaloacetate, ETC: electron transport chain 

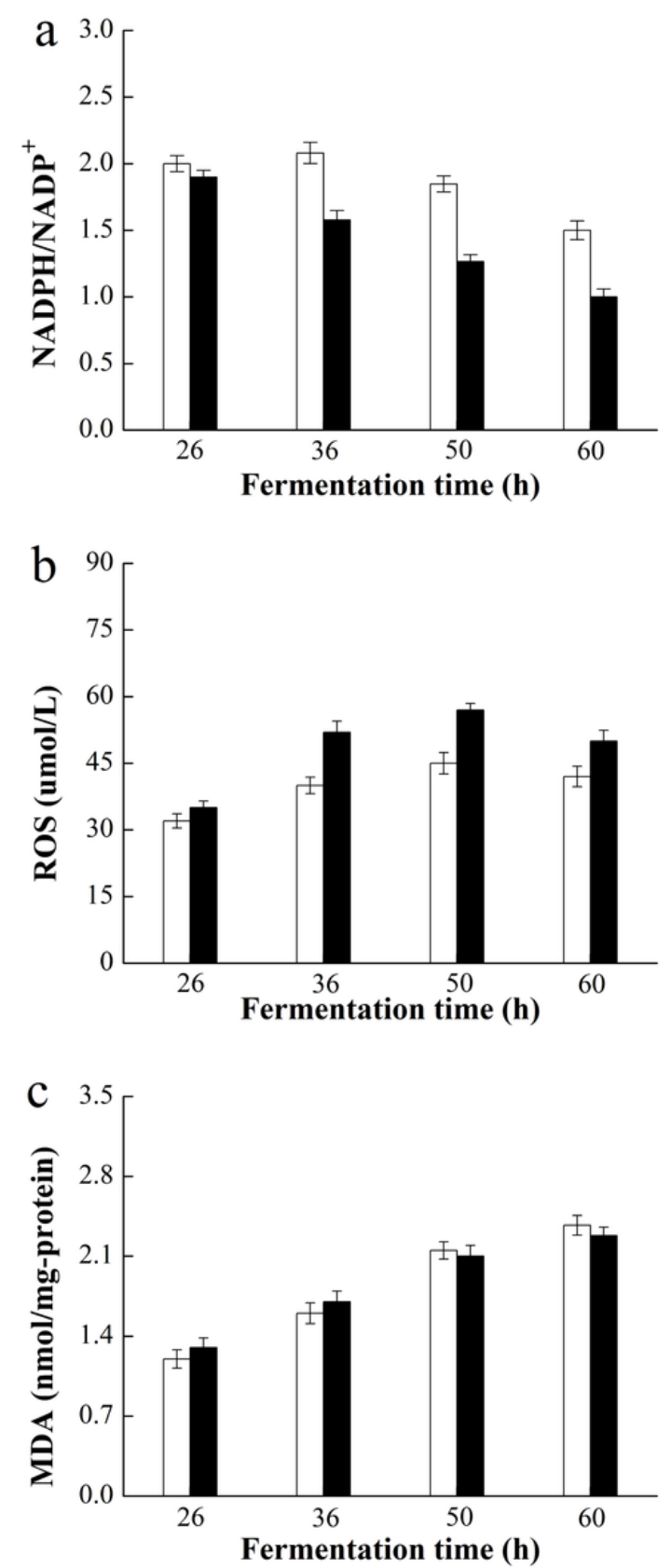

Figure 5

The effects of citrate on intracellular redox state and cell damage degree White bar: control; black bar: with $3 \mathrm{~g} / \mathrm{L}-\mathrm{broth}$ sodium citrate added at $24 \mathrm{~h}$ 